\title{
Proton beam lifetime increase with 10- and 12-pole correctors in the Relativistic Heavy Ion Collider
}

\author{
W. Fischer, J. Beebe-Wang, X. Gu, \\ Y. Luo, S. Nemesure
}

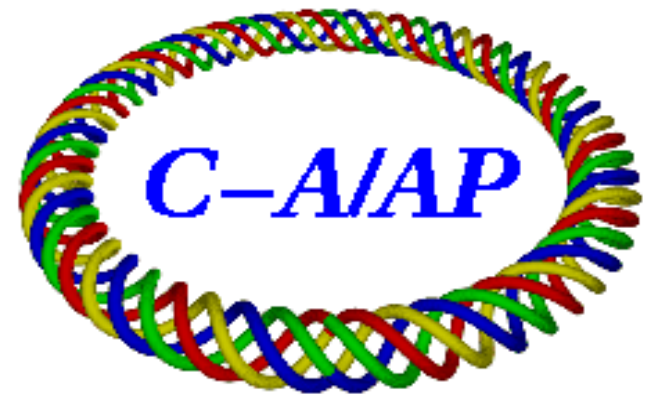

Collider-Accelerator Department

Brookhaven National Laboratory

Upton, NY 11973

Notice: This document has been authorized by employees of Brookhaven Science Associates, LLC under Contract No. DE-AC02-98CH10886 with the U.S. Department of Energy. The United States Government retains a nonexclusive, paid-up, irrevocable, world-wide license to publish or reproduce the published form of this document, or allow others to do so, for United States Government purposes. 


\title{
Proton beam lifetime increase with 10- and 12-pole correctors in the Relativistic Heavy Ion Collider
}

\author{
W. Fischer, ${ }^{*}$ J. Beebe-Wang, X. Gu, Y. Luo, and S. Nemesure \\ Brookhaven National Laboratory, Upton, NY 11973, USA
}

\begin{abstract}
10- and 12-pole correctors were installed in a number of machines and are also considered for future machines. In the Relativistic Heavy Ion Collider (RHIC) 10- and 12-pole correctors exist to correct for the detrimental effects of magnetic field errors in the interaction region magnets. These field errors in conjunction with beam-beam effects and parameter modulations dominate the beam lifetime in polarized proton operation. During the 2009 polarized proton run 10- and 12pole correctors were set through an iterative procedure, and used for the first time operationally in one of the beams. We report on the procedure to set these high-order multipole correctors, compare the found values with calculated ones, estimate the effect of the new corrector settings on the integrated luminosity, and calculate the effect of both the calculated and experimentally found corrector strengths on the dynamic aperture.
\end{abstract}

PACS numbers: 29.20.D-, 05.45.-a

\section{INTRODUCTION}

Correctors are an integral part of many storage rings and beam lines. Dipole correctors are used for orbit correction, quadrupole correctors for tune and $\beta$-beat correction, sextupoles for chromaticity adjustments, and octupoles to suppress instabilities. Sextupoles and octupoles are also employed to correct for magnetic field errors, typical for superconducting magnets where the field quality is given by the conductor placement and possibly persistent currents rather than the geometry of pole tips. A large number of references exists for these types of correctors and their use.

Decapoles (10-poles) and dodecapoles (12-poles) are used much less frequently, and we found no reports of correctors with more than 12 poles in the literature. 10and 12-pole correctors were installed in a number of machines and are also considered for future machines. Perhaps the earliest installation of 10-pole correctors was in the Daresbury Synchrotron Radiation Source (SRS), were they were the highest order multipole correctors in corrector packages. It was planned to use octupoles and 10-poles to study beam resonances and instabilities [1].

In the DESY Hadron-Elektron Ring Anlage (HERA) proton ring 10- and 12-pole correctors were installed in the arcs to correct for large systematic magnetic field errors in the dipoles and quadrupoles respectively, thereby increasing the dynamic aperture. At injection energy the dynamic aperture was particularly limited due to time-dependent persistent currents [2-7]. 10-pole correctors ran typically with $60 \%$ of the average integrated strength measured in all arc dipole magnets, and the 12-pole correctors with $100 \%$ of the average integrated strength measured in all arc quadrupole magnets. Tests were made during which the beam lifetime was observed with varying corrector strength, including a polarity re-

*Electronic address: Wolfram.Fischer@bnl.gov versal of half of the correctors. No clear effect on the beam lifetime could be established [8].

For the same reason 10- and 12-pole arc correctors were installed in HERA-p, 10-pole correctors were also considered for the Superconducting Super Collider (SSC) [916]. In the Brookhaven Relativistic Heavy Ion Collider (RHIC) [17] 10-pole correctors in the arcs were studied [18], and 10-pole windings are part of the arc corrector packages [19]. Initially the 10-pole arc correctors were not connected to power supplies and over the first decade of operation the beam lifetime at injection was found to be sufficient for operation without these correctors. RHIC also has 10- and 12-pole correctors, with power supplies installed, in the interaction region (IR) quadrupole triplets (Fig. 1) [17, 19]. These were installed because an analysis of the triplet errors suggested that such correctors may be needed to improve the dynamic aperture and beam lifetime [20-22]. At the time it was anticipated that the corrector strengths can be set to calculated values based on measured field errors. We will report later how the calculated values compare to values found in an iterative experimental procedure. A different method to determine field errors experimentally was developed during the early RHIC years, based on observed tune shifts with orbit bumps in the magnets of interest $[23,24]$. It has since been used to set sextupole and skew sextupole correctors.

Following the HERA proton ring and the SSC design, the CERN Large Hadron Collider (LHC) also has 10pole correctors installed in the arcs $[25,26]$. It was also concluded early in the design that in operation with low $\beta^{*}$ a correction of the IR multipole errors may be needed [27-29]. The LHC IR triplets have a nonlinear multipole correction system that resembles the RHIC system $[25,26,30]$ with sextupole, skew-sextupole, octupole, skew-octupole, and 12-pole correctors. 10-pole correctors were deemed unnecessary since the LHC IR does not have a dipole-first layout with associated 10pole errors in dipoles. Arc 10- and 12-pole correctors had been studied with calculations and simulations [31- 


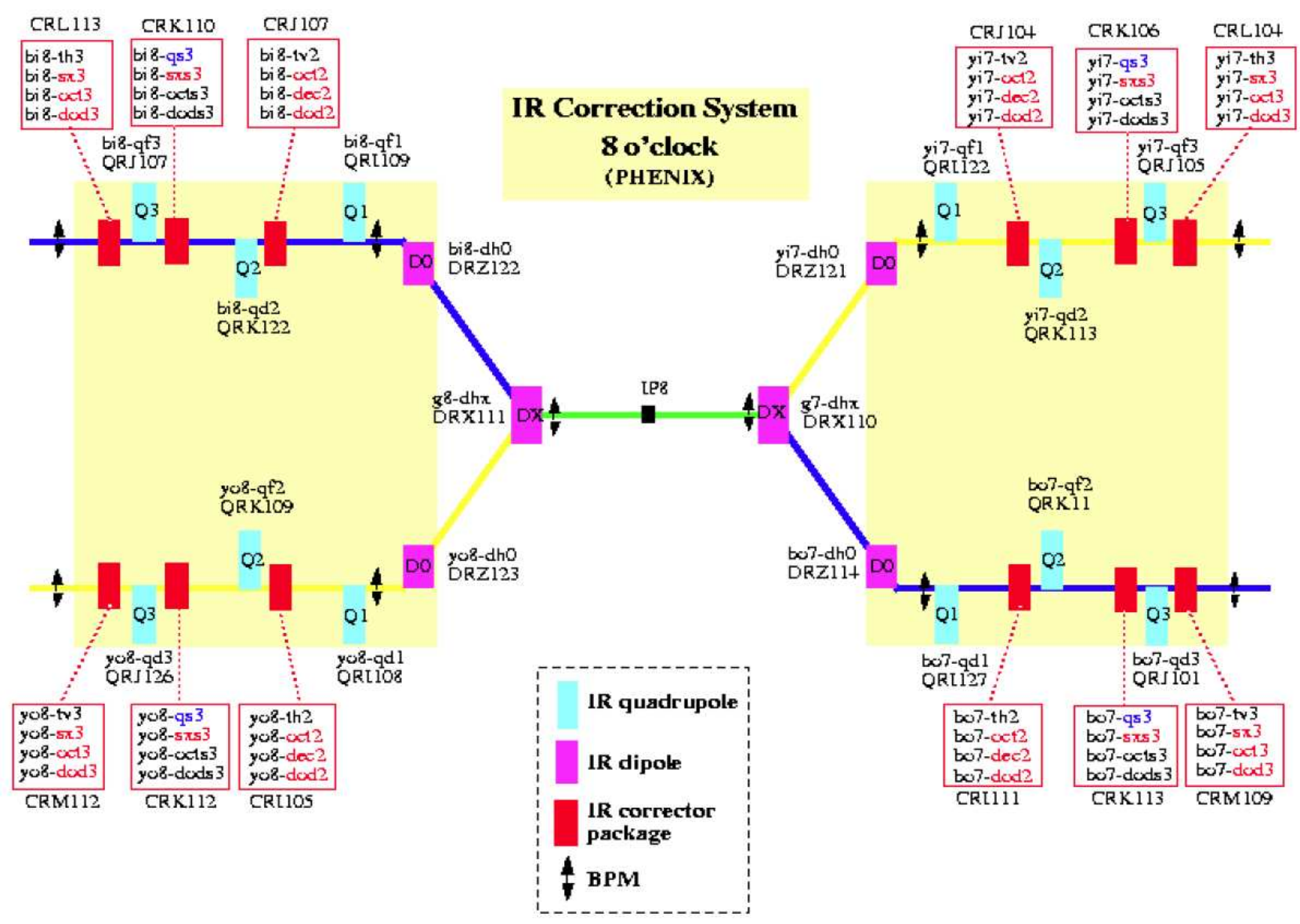

FIG. 1: Layout of an RHIC interaction region with dipoles (DX, D0), quadrupoles (Q1, Q2, Q3), horizontal and vertical orbit correctors (th, tv), skew quadrupoles (qs), sextupoles (sx), skew sextupoles (sxs), octupoles (oct), decapoles (dec), and dodecapoles (dod) [24]. Shown is the one of the six interaction regions that includes the PHENIX experiment. A designation like "bi8-" stands for "Blue ring", "inner arc", "sector 8", "yo8-" for "Yellow ring", "outer arc", "sector 8", etc.

35], and 10-pole correctors were used in a test to correct the nonlinear chromaticity at injection [36]. The IR corrector scheme had been extensively studied during the LHC design phase [37-46]. It is now being studied for the ongoing effort to increase the luminosity [47] as well as for upgrades [48]. It was anticipated that the higher order correctors will be set to calculated values based on magnet measurements, or determined experimentally either with dedicated time $[23,49]$ or parasitic to physics operation [49]. Neither the arc 10-pole correctors, nor the IR 12-pole correctors have been used to date. Nonlinear IR correctors were expected to become relevant with a beam envelope function at the interaction point $\beta^{*} \leq 1.1 \mathrm{~m}[47]$. However, the LHC operated with $\beta^{*}=60 \mathrm{~cm}$ at an energy of $4 \mathrm{TeV}$ (below the design energy of $7 \mathrm{TeV}$ ) in 2012 [50] without the need for these correctors.

10-pole magnets are under consideration for the Compact Linear Collider (CLIC) beam delivery system to minimize the beam size at the interaction point [51], and skew 10-poles are considered for the KEK ATF upgrade to correct high-order aberrations [52]. 10-pole correctors were designed for the Brookhaven National Synchrotron Light Source II (NSLS-II) [53] to correct the nonlinear momentum dependence of the optics and are also considered for other future light sources to realize ultra-low emittances and attain sufficient dynamic aperture [54].

Despite the fact that 10- and 12-pole correctors were installed in a number of machines, to date no operational benefit has been reported for the use of these correctors. Our goal was to study the use of these correctors experimentally in RHIC, compare the corrector values that are found to minimize the beam loss rate to calculated values based on measured magnetic field errors, and estimate the gain in integrated luminosity.

\section{THE RELATIVISTIC HEAVY ION COLLIDER}

The Relativistic Heavy Ion Collider [17] at Brookhaven National Laboratory has been in operation since 2000. 
RHIC is the first and one of two existing heavy ion colliders (the other one being the LHC), and the only existing polarized proton collider. So far six combinations of particle species collided (U-U, $\mathrm{Au}-\mathrm{Au}, \mathrm{d}-\mathrm{Au}, \mathrm{Cu}-\mathrm{Au}$, $\mathrm{Cu}-\mathrm{Cu}$, polarized p-p), at 15 different center-of-mass energies [55-57]. The highest energies are $100 \mathrm{GeV} /$ nucleon for $\mathrm{Au}$ and $255 \mathrm{GeV}$ for polarized protons. Over the last decade the heavy ion luminosity increased by two orders of magnitude and exceeds the design luminosity by a factor of 15 . The polarized proton luminosity increased by more than one order of magnitude, and the average store polarization reached $59 \%$ and $52 \%$ at $100 \mathrm{GeV}$ and $255 \mathrm{GeV}$ respectively. At the highest rigidities the beams are in collision about $60 \%$ of calendar time (including all interruptions such as setup, maintenance, failures, and accelerator physics experiments) [55-57]. The two superconducting rings are referred to as the Blue and Yellow ring.

In heavy ion operation the most fundamental luminosity limit is intrabeam scattering [56, 58], addressed with bunched beam stochastic cooling $[59,60]$. In polarized proton operation emittance growth rates from intrabeam scattering are an order of magnitude smaller than for heavy ions, but the beam-beam parameter is about three times larger. The main effects affecting the proton beam lifetime in RHIC are the beam-beam interaction, nonlinear errors in the IR magnets, and parameter modulations like $10 \mathrm{~Hz}$ orbit variations stemming from mechanical triplet vibrations [61, 62]. At $100 \mathrm{GeV}$ (below the maximum proton energy of $255 \mathrm{GeV}$ ) nonlinear single particle effects are particularly enhanced since, unconstrained by current limits, low $\beta^{*}$ values can be created and the un-normalized emittance is larger. These lead to larger beam sizes in the IR triplet magnets than at full energy, and larger nonlinear magnet errors are sampled. It is this situation where we study the effect of 10 - and 12-pole correctors.

\section{BEAM AND LUMINOSITY LIFETIMES IN 100 GEV POLARIZED PROTON OPERATION}

Table I lists the main lattice and beam parameters for the polarized proton operation in 2009. The reduction of $\beta^{*}$ at the two experiments PHENIX and STAR from $1.0 \mathrm{~m}$ in 2008 to $0.7 \mathrm{~m}$ in 2009 [63], together with a reduction in the transverse emittance by $25 \%[64,65]$ led to a significant reduction in the beam and luminosity lifetimes.

The time dependent beam intensities $N(t)$ and luminosities $\mathcal{L}(t)$ can be well fitted to a sum of two exponential functions:

$$
N(t)=N(0)\left[A e^{-t / \tau_{1}}+(1-A) e^{-t / \tau_{2}}\right]
$$

and

$$
\mathcal{L}(t)=\mathcal{L}(0)\left[A e^{-t / \tau_{1}}+(1-A) e^{-t / \tau_{2}}\right]
$$

TABLE I: Parameters for RHIC polarized proton operation at $100 \mathrm{GeV}$ in 2009.

\begin{tabular}{lcc}
\hline \hline quantity & unit & value \\
\hline total energy $E_{p}$ & $\mathrm{GeV}$ & 100 \\
$\beta_{x, y}^{*}$ at IP6, IP8 & $\mathrm{m}$ & 0.7 \\
lattice tunes $\left(Q_{x}, Q_{y}\right)$ & $\ldots$ & $(0.695,0.685)$ \\
no of bunches & $\ldots$ & 109 \\
bunch intensity $N_{p}$, initial & $10^{11}$ & 1.35 \\
$\mathrm{rms}$ emittance $\epsilon_{n}$, initial & $\mathrm{mm} \mathrm{mrad}$ & 2.5 \\
${\mathrm{rms} \mathrm{bunch} \mathrm{length} \sigma_{s}, \text { initial }}_{\mathrm{rms} \text { momentum spread }}{ }^{b} \delta p / p$ & $\mathrm{~m}$ & 0.85 \\
hourglass factor $^{b} F$, initial $^{-3}$ & 0.4 \\
beam-beam parameter $\xi / \mathrm{IP}$ & $\ldots$ & 0.70 \\
number of beam-beam IPs & $\ldots$ & 0.007 \\
\hline \hline
\end{tabular}

${ }^{a}$ For $V_{\text {gap }}=300 \mathrm{kV}$. Lower voltages were also used.

${ }^{b}$ The hourglass factor $F$ gives the luminosity reduction due to long bunches. $\mathrm{F}$ becomes significantly smaller than 1 for $\sigma_{s} \gtrsim \beta^{*}[66]$.

where $N(0)$ and $\mathcal{L}(0)$ are the initial intensity and luminosity respectively, and $\left(A, \tau_{1}, \tau_{2}\right)$ are fit parameters. The fit parameters are not based on a specific physical model, but allow a reliable fit under widely varying conditions. Table II shows the average fit parameters for all physics stores in 2008 and 2009, where the fits extend over the first $3 \mathrm{~h}$ of the stores.

TABLE II: Fitted parameters $\left(A, \tau_{1}, \tau_{2}\right)$ for the time dependent Blue intensities $N_{B}(t)$, Yellow intensities $N_{Y}(t)$, and luminosities $\mathcal{L}(t)$ (Eqs. (1) and (2)) for the RHIC polarized proton operation at $100 \mathrm{GeV}$ in 2008 and 2009 .

\begin{tabular}{lcc}
\hline \hline quantity & 2008 & 2009 \\
\hline no of stores & 47 & 148 \\
$N_{B}(t)$ fit & $(9.5 \%, 0.34 \mathrm{~h}, 46.1 \mathrm{~h})$ & $(10.6 \%, 0.40 \mathrm{~h}, 32.7 \mathrm{~h})$ \\
$N_{Y}(t)$ fit & $(3.7 \%, 0.25 \mathrm{~h}, 81.1 \mathrm{~h})$ & $(8.9 \%, 0.43 \mathrm{~h}, 26.1 \mathrm{~h})$ \\
$\mathcal{L}(t)$ fit & $(12.1 \%, 0.39 \mathrm{~h}, 12.4 \mathrm{~h})$ & $(17.9 \%, 0.46 \mathrm{~h}, 7.4 \mathrm{~h})$ \\
\hline \hline
\end{tabular}

In an effort to restore the luminosity lifetime to the 2008 values 10 - and 12-pole corrector settings in the Yellow beam were used in 2009, in addition to the sextupole and skew sextupole settings already in use [23, 24, 67-70].

\section{CALCULATION OF CORRECTOR STRENGTHS}

The magnetic field errors can be expressed as coefficients $\left(b_{n}, a_{n}\right)$ of the field expansion

$$
B_{y}+i B_{x}=B_{0}\left[1+\sum_{n=1}^{\infty}\left(b_{n}+i a_{n}\right)\left(\frac{x+i y}{r_{0}}\right)^{n}\right] .
$$

where $i$ is the imaginary unit, and $(x, y)$ denote the horizontal and vertical coordinates. $\left(B_{x}, B_{y}\right)$ are the field components in the $(x, y)$ directions respectively, and $B_{0}$ is a reference field strength (typically $B_{y}$ at $(x, y)=\left(r_{0}, 0\right)$ ). 
TABLE III: Selected integral multipole errors in the RHIC IR magnets, quoted in units of $10^{-4}$ of the dipole field at the reference radius $r_{0}$ and for $100 \mathrm{GeV}$ proton energy. Shown are 10 - and 12-poles $\left(b_{5} l\right.$ and $\left.b_{6} l\right)$ as well as the next significant multipole errors.

\begin{tabular}{lccc}
\hline \hline magnet & multipole $^{a}$ & mean & $\mathrm{rms}$ \\
\hline DX $\left(r_{0}=60 \mathrm{~mm}\right)$ & $b_{3}$ & -1.12 & 1.89 \\
(6 magnets $)$ & $b_{5}$ & -3.06 & 0.46 \\
& $b_{7}$ & -1.84 & 0.10 \\
& $b_{9}$ & -1.09 & 0.07 \\
& $b_{11}$ & -1.13 & 0.02 \\
\hline D0 $\left(r_{0}=31 \mathrm{~mm}\right)$ & $b_{3}$ & 0.15 & 1.38 \\
$(24$ magnets $)$ & $b_{5}$ & 0.46 & 0.30 \\
& $b_{7}$ & 0.22 & 0.07 \\
\hline Q1 $\left(r_{0}=40 \mathrm{~mm}\right)$ & $b_{4}$ & -0.01 & 0.74 \\
$(26$ magnets $)$ & $b_{6}$ & 1.19 & 0.73 \\
\hline Q2 $\left(r_{0}=40 \mathrm{~mm}\right)$ & $b_{4}$ & -0.61 & 0.36 \\
$(27$ magnets $)$ & $b_{6}$ & -0.65 & 0.63 \\
\hline Q3 $\left(r_{0}=40 \mathrm{~mm}\right)$ & $b_{4}$ & -1.55 & 1.04 \\
$(13$ magnets $)$ & $b_{6}$ & 0.08 & 0.29 \\
\hline \hline
\end{tabular}
${ }^{a}$ Integral errors are given by $b_{n, \text { integral }}\left[10^{-4}\right]=b_{n, \text { body }}\left[10^{-4}\right]+$
$\left\{b_{n} l_{\text {lead end }}\left[10^{-4} \mathrm{~m}\right]+b_{n} l_{\text {return end }}\left[10^{-4} \mathrm{~m}\right]\right\} / l_{\text {magnet }}[\mathrm{m}]$.

The reference radius $r_{0}$ is chosen so that field errors are evaluated at amplitudes $(x, y)$ of interest. The $b_{n}$ are called "normal" and the $a_{n}$ skew coefficients, and are usually quoted in units of $10^{-4} \cdot b_{1}$ denotes a dipole coefficient, $a_{2}$ a skew quadrupole coefficient etc. [79].

There are several ways to correct the local IR nonlinear field errors based on the lattice model [20, 37, 71]. The action-angle kick minimization is fast and simple $[20,71]$. It has been used to calculate corrector values for RHIC and LHC simulations that were used to design the higher order correction system in these machines [38, 41-46]. Later LHC studies used the algorithm reported in Ref. [37], that minimizes resonance driving terms. For this algorithm the number of resonances to be corrected must be matched by the number of correctors, and the system is under-constrained when not enough correctors are installed. When the number of correctors matches the number of resonances to be corrected, the algorithm is identical to the one in [20, 71].

We now illustrate the action-angle minimization [20, 71]. To minimize the action change for an IR passage through nonlinear multipole errors of a certain order, we minimize the following two quantities simultaneously,

$$
\int_{L} d s C_{z} c_{n}+(-1)^{n} \int_{R} d s C_{z} c_{n}, \quad z=x, y
$$

where $L$ and $R$ mean the left and right sides of the interaction region, $c_{n}$ stands for the normal or skew field errors $b_{n}$ or $a_{n}$. $n$ is the order of multipole error. For 10 -pole and 12 -poles, $n$ is 5 and 6 respectively. $C_{z}$ is the weight factor,

$$
\begin{aligned}
& C_{x}= \begin{cases}\beta_{x}^{n / 2} & \text { for } b_{n} \\
\beta_{x}^{(n-1) / 2} \beta_{y}^{1 / 2} & \text { for } a_{n}\end{cases} \\
& C_{y}= \begin{cases}\beta_{y}^{n / 2} & \text { for even } b_{n} \text { or odd } a_{n} \\
\beta_{x}^{1 / 2} \beta_{y}^{(n-1) / 2} & \text { for odd } b_{n} \text { or even } a_{n}\end{cases}
\end{aligned}
$$

For each order, there are two quantities to be minimized, one in the horizontal plane, one in the vertical plane. A natural choice is to place at least one corrector at either side of the interaction region. For 10 -poles we minimize the quantities

$$
\begin{aligned}
\int_{L} d s \beta_{x}^{5 / 2} b_{5} & -\int_{R} d s \beta_{x}^{5 / 2} b_{5} \text { and } \\
\int_{L} d s \beta_{x}^{1 / 2} \beta_{y}^{2} b_{5} & -\int_{R} d s \beta_{x}^{1 / 2} \beta_{y}^{2} b_{5},
\end{aligned}
$$

and for 12-poles the quantities

$$
\begin{aligned}
& \int_{L} d s \beta_{x}^{3} b_{6}+\int_{R} d s \beta_{x}^{3} b_{6} \text { and } \\
& \int_{L} d s \beta_{y}^{3} b_{6}+\int_{R} d s \beta_{y}^{3} b_{6} .
\end{aligned}
$$

The triplets near the two experiments STAR (IR6) and PHENIX (IR8) are equipped with multipole magnets to correct the nonlinear magnetic errors of the IR magnets, namely the beam separation dipoles DX and D0, and triplet quadrupoles Q1, Q2 and Q3. Details of the layout can be found in Fig. 1. Each triplet contains one 10-pole corrector, and two 12-pole correctors. 10-poles are the second allowed harmonic error in dipoles, and 12-poles are the first allowed harmonic in quadrupoles [72].

Table III shows a summary of the 10 - and 12-poles $\left(b_{5}\right.$ and $b_{6}$, see Eq. (3) below) as well as the next significant multipole errors. Figure 2 shows the location and strength of the 10- and 12-pole errors for IR8 the RHIC Yellow ring. There are large contributions from the magnet lead ends. For this reason the Q2 and Q3 magnets have their lead ends next to each other so that the two ends partially compensate each others 12-pole error, and the DX dipole lead ends are pointed towards the IP where the $\beta$-functions are smaller than at the other end.

Table IV displays the corrector strengths $k_{c 1}$ calculated with Refs. [20, 71] and $k_{c 2}$ calculated with Ref. [37]. To calculate the 10-pole corrector strengths with Ref. [37] we zero the coefficients $c\left(b_{5} ; p, q\right)=(0,5)$ and $(5,0)$ (two conditions for two correctors), to calculate the 12-pole corrector strengths we zero the coefficients $c\left(b_{6} ; p, q\right)=$ $(0,6),(2,4),(4,2)$, and $(6,0)$ (four conditions for four correctors). For details on the procedure we refer to Ref. [37].

For the 10-pole correctors the two methods calculate the same strength as explained above. For the 12-pole correctors the two methods differ by up to a factor four for individual correctors (yo5-dod3). However, the phase 


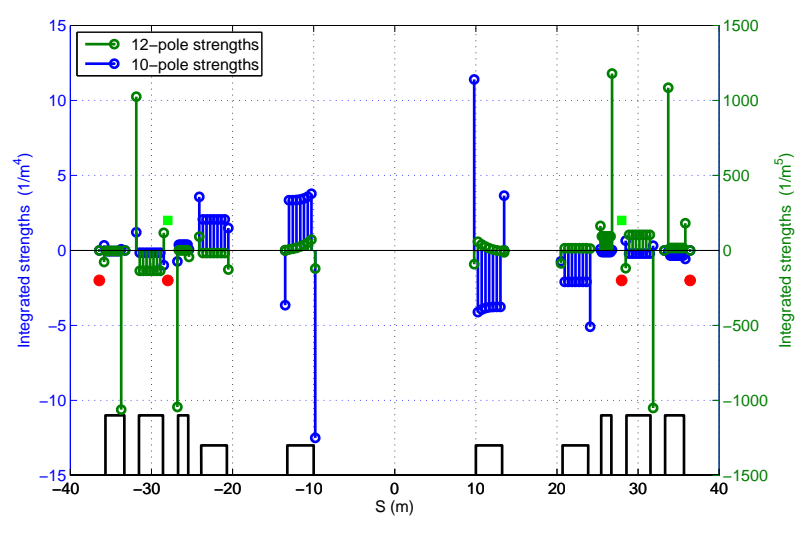

FIG. 2: Location and strength of the 10- and 12-pole errors in the RHIC Yellow IR8. Shown are the integrated strengths as they are used in the model for calculation of the corrector strengths and for tracking. The location is measured from IP8. The 10-pole errors in the beam splitting DX dipoles (beginning at $s=10 \mathrm{~m}$ ) is changing with the $s$-position to take account of the trajectory that is bent out of the magnet center with increasing $s$. The lower part shows the location of the dipoles (single height rectangles), quadrupoles (double height rectangles), and correctors (red dots, also see Fig. 1).

advance in both transverse planes between the dod 2 and $\operatorname{dod} 3$ correctors is only $0.5 \mathrm{deg}$, and optically the two correctors are almost the same. It is therefore more meaningful to compare the sum of the $\operatorname{dod} 2$ and $\operatorname{dod} 3$ strengths. The differences range from $3 \%$ (yi7) to $74 \%$ (yo5), and give an indication of what agreement one can hope to achieve with experimental values.

\section{EXPERIMENTAL DETERMINATION OF 10- AND 12-POLE CORRECTOR STRENGTHS}

We determined the optimum corrector strengths experimentally through direct observation of the beam loss rate. We chose to monitor the beam loss rate directly for a number of reasons. First, the beam loss rate is what we would like to minimize. It is the most direct signal and any other method would also need to measure the effect on the beam loss rate eventually. Second, the effect of the 10- and 12-pole correctors on the beam loss rate is small enough so that scans of the corrector strengths can be done parasitically to physics operation. This allows for much more measurement time than available in dedicated experiments. Third, the direct observation of the beam loss rate offered a better signal-to-noise ratio than the method used to set sextupoles and skew sextupoles $[23,24,67-69]$ since the tune changes due to orbit bumps and high-order multipoles are small. We note that in Ref. [73] a method was proposed to measure 12poles components in the LHC triplets using a modulated instead of a static closed orbit bump, which allows for an increase the signal-to-noise ratio.

A generic optimization scanner program (Fig. 3) that adjusts independent variables in order to optimize one or more dependent variables was employed to find the optimum corrector strengths. While scans can be and have been done manually, the time required to complete a scan and the high probability of errors make manual scans impractical. In our case the independent variables are the 10- and 12-pole corrector strengths, and the dependent variable is the observed beam loss rate $R(t)=(1 / N(t))(d N(t) / d t)$ (Figs. 3 and 4$)$. The beam loss rate is calculated over a $20 \mathrm{~s}$ interval with a $1 \mathrm{~Hz}$ update rate from the beam current measured by a DCCT $[74,75]$.

The scanner program takes a set of initial conditions that include magnet strength, step size, and delay. There are optional boundary conditions for the magnet current read back to prevent damage to power supplies. When the user initiates the optimization task, the program sets the initial magnet strength and sits at that value for a user defined time. The data collected during this time is averaged and graphically displayed along with a standard deviation before moving on to the next magnet strength defined by the step size (Fig. 3). Once the magnet has settled at the new set point the program collects more data. After the data for the second point has been collected the program decides where to set the next current by comparing the data from the current average to the previous one. If the trend of the current read back is continuing in the optimized direction, the program continues to set the strength in the same direction. If the read back is less optimal the program will change the direction for the next magnet set point. This process continues until a locally optimized value has been found. The centrally optimized value along with the points collected to either side are then fit to a Gaussian. The peak of this Gaussian is determined to be the optimal magnet strength. If no local extremum is found before reaching a boundary condition, the boundary condition value will be used.

In preliminary tests the step sizes for the corrector strengths and integration times were determined. The step sizes were chosen large enough so that a clear change in the beam loss rate could be observed. The integration time must be long enough so that statistical variations in the observed signal are averaged out sufficiently. With longer integration times, smaller step sizes are possible. The step size also provides a resolution limit, which is important in interpreting the experimental results. The preliminary tests also showed that the beam lifetime is more sensitive to the 12-pole correctors than to the 10pole correctors. We therefore started the scans with the 12-pole correctors.

The correctors were always scanned in the same order, beginning with the 12-poles and followed by the 10poles. The order of the correctors is the same as shown in Tab. V. The two 12-pole correctors per triplet, separated by only 0.5 deg phase advance in both transverse planes, were not scanned consecutively to avoid mutually can- 
TABLE IV: Comparison of 10- and 12-pole corrector values calculated and found experimentally. The experimentally found values are quoted in terms of the integrated absolute strengths, and in terms of the step size $k_{s}$ used in the measurements. The steps size is $k_{s}=750 \mathrm{~m}^{-5}$ for the 12 -pole correctors, and $k_{s}=5 \mathrm{~m}^{-4}$ for the 10 -pole correctors (Tab. V). The phase advance between two correctors for which the sum is also shown, for example yo5-dod 2 and yo5-dod3, is 0.5 deg and we compare only the sum values.

\begin{tabular}{|c|c|c|c|c|c|c|}
\hline corrector & $\begin{array}{c}\text { calculated } \\
\text { strength } \\
\text { Refs. }[20,71] \\
k_{c 1} \\
\end{array}$ & $\begin{array}{c}\text { calculated } \\
\text { strength } \\
\text { Ref. [35] } \\
k_{c 2} \\
\end{array}$ & $k_{e}$ & $\begin{array}{l}\text { entally } \\
\text { rength }\end{array}$ & comparison & comparison \\
\hline \multicolumn{7}{|c|}{ 12-pole correctors } \\
\hline & {$\left[\mathrm{m}^{-5}\right]$} & {$\left[\mathrm{m}^{-5}\right]$} & {$\left[\mathrm{m}^{-5}\right]$} & {$\left[k_{s}\right]$} & {$[\ldots]$} & {$[\ldots]$} \\
\hline yo5-dod3 & +902 & -238 & +584 & +0.8 & & \\
\hline yo5-dod 2 & +2345 & -1625 & +480 & +0.6 & & \\
\hline sum & +3247 & -1863 & +1064 & & +0.33 & -0.57 \\
\hline yi6-dod2 & -961 & +1736 & -3012 & -4.0 & & \\
\hline yi6-dod3 & -1131 & +752 & +2982 & +4.0 & & \\
\hline sum & -2092 & +2488 & -30 & & +0.01 & -0.01 \\
\hline yi7-dod3 & -1058 & +568 & -2666 & -3.5 & & \\
\hline yi7-dod2 & -1025 & +1461 & -485 & -0.6 & & \\
\hline sum & -2083 & +2029 & -3151 & & +1.51 & +1.55 \\
\hline yo8-dod2 & +1166 & -2280 & +2502 & +3.3 & & \\
\hline yo8-dod3 & +727 & -337 & -509 & -0.7 & & \\
\hline sum & +1893 & -2617 & +1999 & & +1.0 & +0.76 \\
\hline \multicolumn{7}{|c|}{ 10-pole correctors } \\
\hline & {$\left[\mathrm{m}^{-4}\right]$} & {$\left[\mathrm{m}^{-4}\right]$} & {$\left[\mathrm{m}^{-4}\right]$} & {$\left[k_{s}\right]$} & {$[\ldots]$} & {$[\ldots]$} \\
\hline yo5-dec2 & -6.4 & -6.4 & +4.4 & +0.9 & -0.69 & -0.69 \\
\hline yi6-dec2 & +9.6 & +9.6 & +15.9 & +3.2 & +1.66 & +1.66 \\
\hline yi7-dec2 & +9.4 & +9.4 & +32.2 & +6.4 & +3.42 & +3.42 \\
\hline yo8-dec2 & -9.8 & -9.8 & +0.7 & +0.1 & -0.07 & -0.07 \\
\hline
\end{tabular}

cellation. We see later that this is not sufficient. After three iterations the 10-pole corrector strengths did not change significantly any more and an average of the previous scans was used in the following 12-pole scans. Four of the 12-pole correctors were not scanned any further after another iteration, using again an average of previous scans as the final value. For the remaining 12-poles three more iterations were done. The results of all scans are shown in Tab. V.

In fill 10968 an 8-pole scan was done in addition to the 10- and 12-pole scan but did not result in a measurable reduction in the beam loss rate. The optimized corrector strengths were used operationally for the remainder of the run (18 stores over a period of five days).

The method of setting the 10- and 12-pole correctors could also be applied to the Blue ring. However, the reported beam loss rate in the Blue ring was more noisy than in Yellow, and a scan of all 10- and 12-poles in IR6 and IR8, which took about an hour in the Yellow ring, would have required about twice as much time in the Blue ring. The 2009 RHIC run came to an end before the Blue ring could be scanned. Since the beam lifetime in the Blue ring is about the same as in Yellow (Tab. II) the noisiness of the Blue beam loss rate as calculated from the DCCT may be instrumental.

\section{COMPARISON OF CALCULATED AND EXPERIMENTAL RESULTS}

The experimentally found 10-pole corrector strengths (shown in Tab. IV) are between 0.1 and 6.4 step sizes $k_{s}$. Step sizes smaller than 1 indicate correctors that are effectively turned off, and two of the four 10-pole correctors (yo5-dec2 and yo8-dec2) fall in this category. The other two 10-pole correctors show strengths larger than the calculated ones, one by more than a factor of three. Since the 10-poles were scanned after the 12-poles their final settings may be influenced by 12 -pole settings.

The experimentally found 12-pole corrector strengths are between 0.6 and 4.0 step sizes $k_{s}$. We noted already in Sec. IV that because the dod 2 and $\operatorname{dod} 3$ correctors have only 0.5 deg phase advance between them, it is more meaningful to compare the sum of these correctors rather than individual correctors. Correctors yi6-dod2 and yi6-dod3 have almost the same strength but different sign and compensate each other. (To avoid such a problem both correctors could be forced to have the same strength, or only one of the correctors is used.) For the other three IR triplets the differences between measured and calculated strengths range from $24 \%$ to $57 \%$, which is of the same order as the difference between the two different calculated strengths $k_{c 1}$ and $k_{c 2}$ (Sec. IV).

While the experimentally found corrector strengths are 


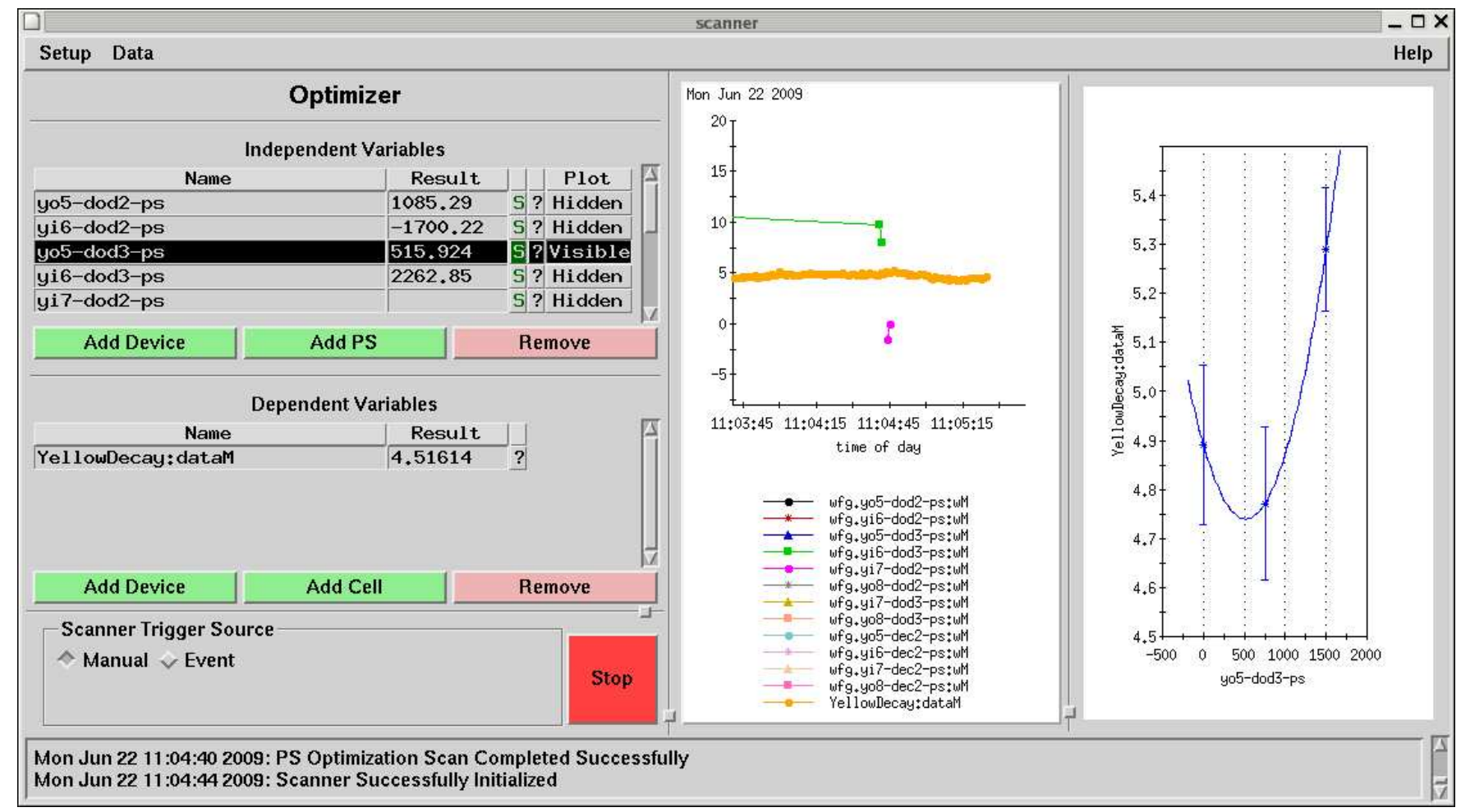

FIG. 3: User interface of a general scanner program used to minimize the beam loss rate with changes in 10- and 12-pole interaction region correctors. The left top list displays the correctors that are part of the scan, and the left middle shows the observable, the beam loss rate calculated from the time-dependent beam current. The left plot displays the beam loss rate and the currents of the magnets during the scan. The right plot displays the measured beam loss rate for each current scanned as well as a parabolic fit to obtain the current for the minimum loss rate.

of the same order of magnitude as the calculated ones for both methods, the overall agreement is not very good.

\section{ESTIMATE OF EFFECT ON INTEGRATED LUMINOSITY}

We now give an estimate for the increase in the integrated luminosity per store with the experimentally found corrector values. To estimate the effect on the integrated luminosity we need:

- An estimate of the difference in the beam loss rate with and without the 10- and 12-pole correctors over the entire length of the store.

- A baseline beam loss rate to which the difference can be applied.

We obtained the data for first item in three different stores, at the beginning and the end of the stores (Tab. VI), and interpolate and extrapolate to cover the entire store length. The data for the second item are obtained from all physics stores (Tab. II). This is the largest data sample available and gives the most reliable estimate for the baseline beam loss rate.
Figure 4 shows the change in the Yellow beam loss rate at the beginning of fill 10998, when the effect of the correctors was largest. The loss rate increases when the correctors are turned off, and after turning them back on the beam loss rate almost returned to the previous value. As the hadron beam undergoes a period of enhanced beam losses, it may also experience some emittance growth during this time. The thus enlarged beam should have a higher loss rate even after the correctors are turned back on. It is also possible that hysteresis effects in the 10- and 12-pole correctors exist.

With the parameterization of Eq. (1) the Yellow time dependent intensity is

$$
N_{Y}(t)=N_{Y}(0)\left[A e^{-t / \tau_{1}}+(1-A) e^{-t / \tau_{2}}\right] .
$$

The average of all 2009 physics stores, fitted over the first $3 \mathrm{~h}$, is $\left(A, \tau_{1}, \tau_{2}\right)=(8.9 \%, 0.43 \mathrm{~h}, 26.1 \mathrm{~h})$ (Tab. II). The increase in the time dependent beam loss rate $R_{Y}(t)=\left(1 / N_{Y}(t)\right)\left(d N_{Y}(t) / d t\right)$ with the measured values in Tab. VI can be parameterized with the set $\left(A, \tau_{1}, \tau_{2}\right)_{\Delta}$ $=(10.4 \%, 0.40 \mathrm{~h}, 21.1 \mathrm{~h})$. The time dependent beam loss rate for both parameter sets $\left(A, \tau_{1}, \tau_{2}\right)$ over the average store length of $T_{\text {store }}=6.1 \mathrm{~h}$ is shown in Fig. 5 .

Since the luminosity is proportional to the Yellow intensity, we now estimate the effect of the 10- and 12-pole 
TABLE V: Summary of 10- and 12-pole corrector scans in the Yellow ring with 100 GeV proton beam in 2009.

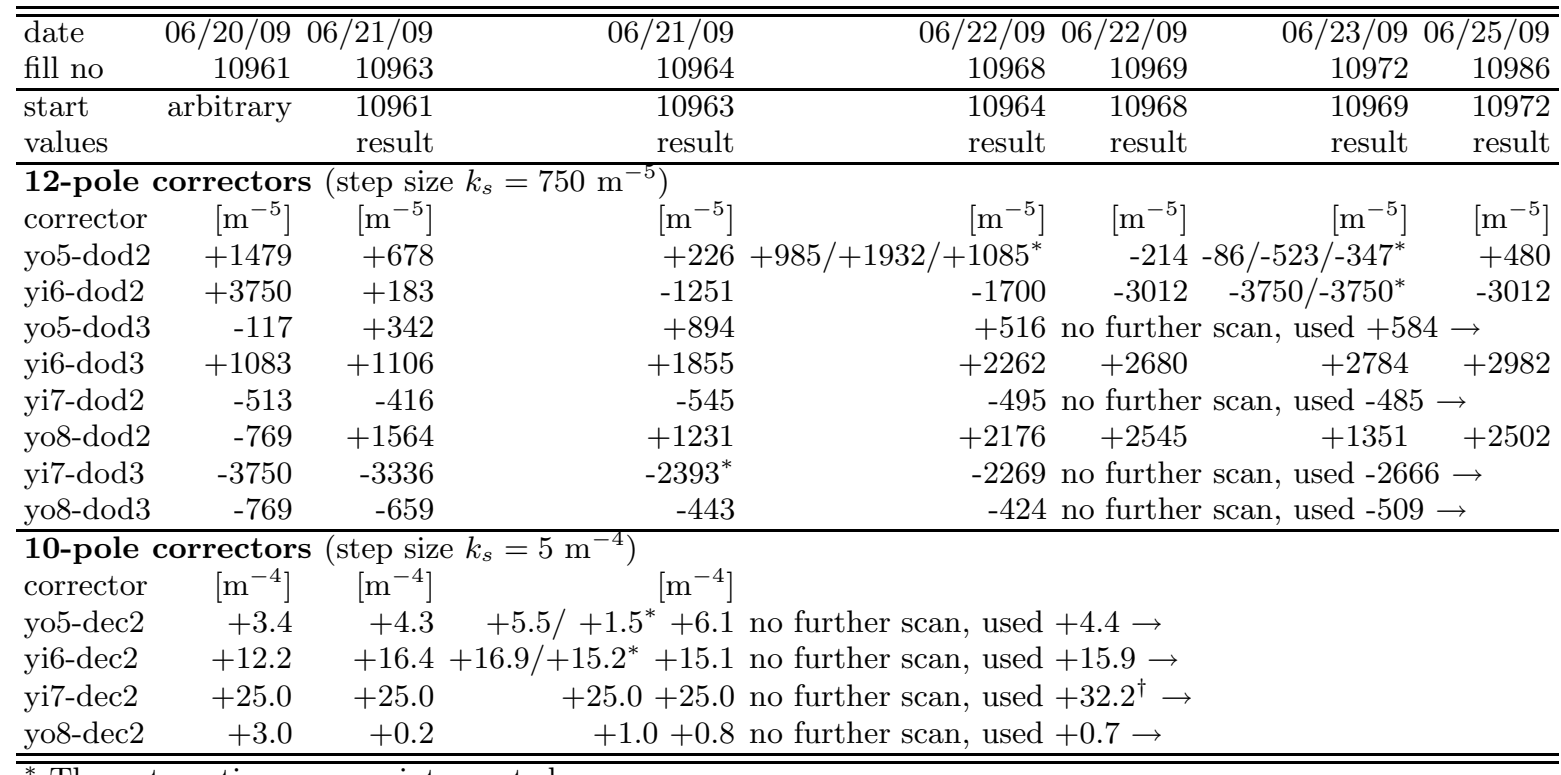

* The automatic scan was interrupted.

${ }^{\dagger}$ At limit in previous scans. $32.3 \mathrm{~m}^{-4}$ is the result of 3 separate scans with increased limit in fill 10968.

TABLE VI: Increase in the Yellow beam loss rate due to turning off of the 10- and 12-pole correctors.

\begin{tabular}{|c|c|c|}
\hline date & fill no rate change & comment \\
\hline $06 / 22 / 09$ & $109684 \rightarrow 5 \% / h$ & $3 \mathrm{~h}$ into store \\
\hline $06 / 26 / 09$ & $109952.7 \rightarrow 3.5 \% / h$ & $5 \mathrm{~h}$ into store \\
\hline $06 / 26 / 09$ & $109989 \rightarrow 11 \% / h$ & $1 / 2 \mathrm{~h}$ into store \\
\hline
\end{tabular}

correctors on the integrated luminosity $L=\int \mathcal{L} d t$ as

$$
\frac{\Delta L}{L}=\frac{\int_{0}^{T_{\text {store }}}\left[N_{Y}(t)-N_{Y \Delta}(t)\right] d t}{\int_{0}^{T_{\text {store }}} N_{Y \Delta}(t) d t} \approx 4.3 \%
$$

where $N_{Y}(t)$ denotes the run-averaged time dependent Yellow intensity with parameters $\left(A, \tau_{1}, \tau_{2}\right)$, and $N_{Y \Delta}(t)$ with parameters $\left(A, \tau_{1}, \tau_{2}\right)_{\Delta}$. We neglect the possible additional improvement from a reduced emittance growth.

\section{SIMULATION OF 10- AND 12-POLE CORRECTOR EFFECT}

To further validate the experimentally found corrector strengths we evaluate their effect on the dynamic aperture (DA) in simulations. We expect to observe an increase in the DA. Increases in the DA cannot be easily translated into increases in the beam lifetime, and lifetime simulations for hadron beams under conditions with strong beam-beam interactions are not reliable enough for direct comparison with experimental data. For completeness we also calculate the effect of the calculated corrector strengths on the DA.

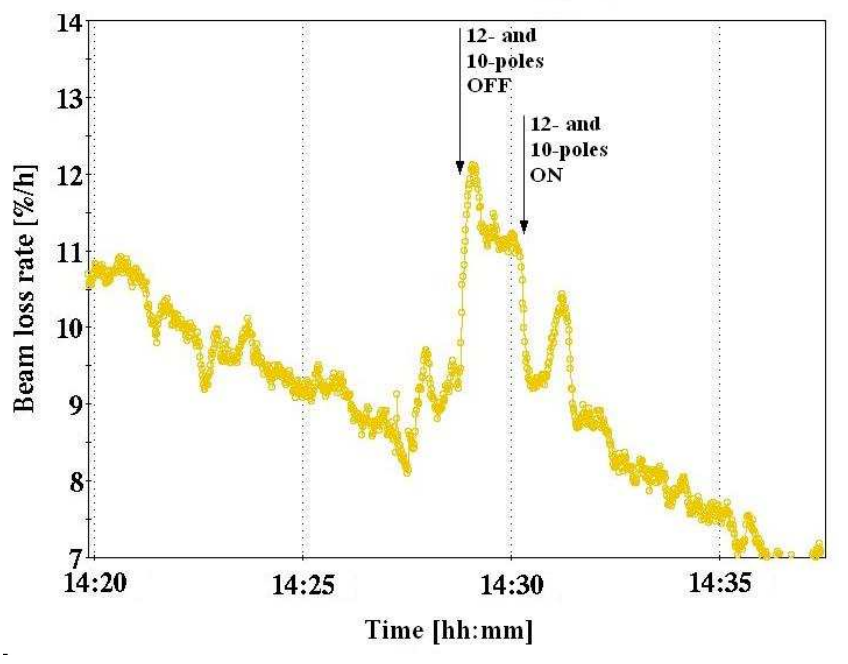

FIG. 4: Yellow beam loss rate with and without 12- and 10pole correctors at the beginning of a polarized proton store (10998).

For the simulation the SimTrack program [76] is used. The lattice model includes all dipoles, quadrupoles, and sextupoles as well as IR magnetic errors for a proton energy of $100 \mathrm{GeV}$ [77]. Magnetic errors were measured during RHIC construction [19], but not all magnets were measured cold. Warm-cold correlations are used to obtain the magnetic errors for magnets that were measured only warm.

For tracking particles have a relative momentum devia- 


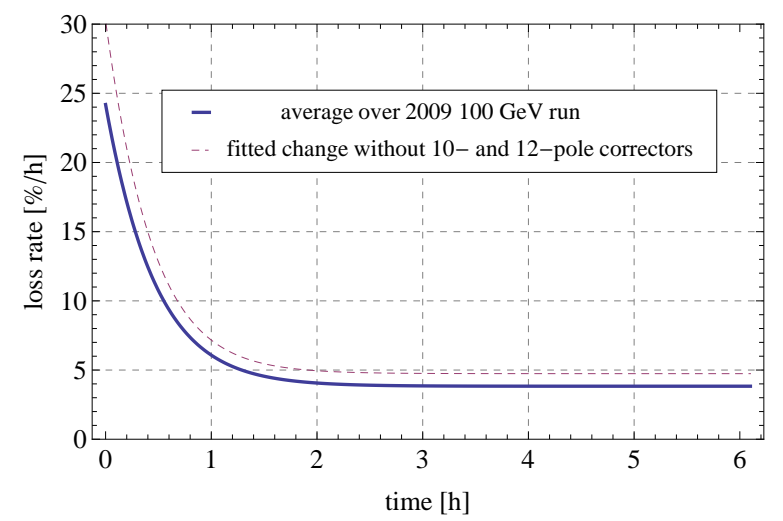

FIG. 5: Time dependent Yellow beam loss rate in the 2009 $\mathrm{GeV}$ polarized proton run, averaged over all physics stores and fitted change due to turning off of 10- and 12-pole correctors.

tion of $\delta p / p=0.0004$ (the initial rms momentum spread, Tab. I). The beam-beam interaction is 6 -dimensional with opposing bunches of intensity $1.2 \times 10^{11}$, and an normalized rms emittance of $3.3 \mathrm{~mm} \cdot \mathrm{mrad}$. The intensity is lower and emittance larger than the ones listed in Tab. I so that the dynamic aperture is calculated for conditions in the middle of a store. Particles are launched along 35 angles in the $x-y$ plane, with a step size of 0.05 rms beam sizes (about $1 \%$ of the dynamic aperture), and tracked over $10^{6}$ turns. The calculated dynamic aperture is quoted in units of the rms beam size.

First, sextupole and skew sextupole IR correctors in IR6 and IR8 were calculated from measured IR errors using the action-angle minimization technique (Sec. IV). The DA for this lattice is obtained and compared with a lattice in which the 10- and 12-pole correctors in IR6 and IR 8 are also used, again set using the action-angle minimization technique. The result is shown in Fig. 6 (a). The 10- and 12-pole correctors increase the DA, averaged over all launch angles, by $4 \%$ from 4.9 to $5.1 \sigma$.

Figure 6 (b) shows the DA calculations for the experimentally determined 10- and 12-pole corrector strengths, and the sextupole and skew sextupole setting present in the machine. These were determined through the minimization of tune changes with local orbit bumps in the triplets $[23,24,67-69]$ and are different from the sextupole and skew sextupole settings calculated for Fig. 6 (a). The dynamic aperture, averaged over all launch angles, increased by $8 \%$ from 4.6 to $5.0 \sigma$.

\section{SUMMARY}

10- and 12-pole correctors were installed in a number of machines, and are also considered for future machines. We reported the first operational use of such correctors, which led to an increase in the integrated luminosity per RHIC store of about $4 \%$ with correctors set in one of the two rings only.
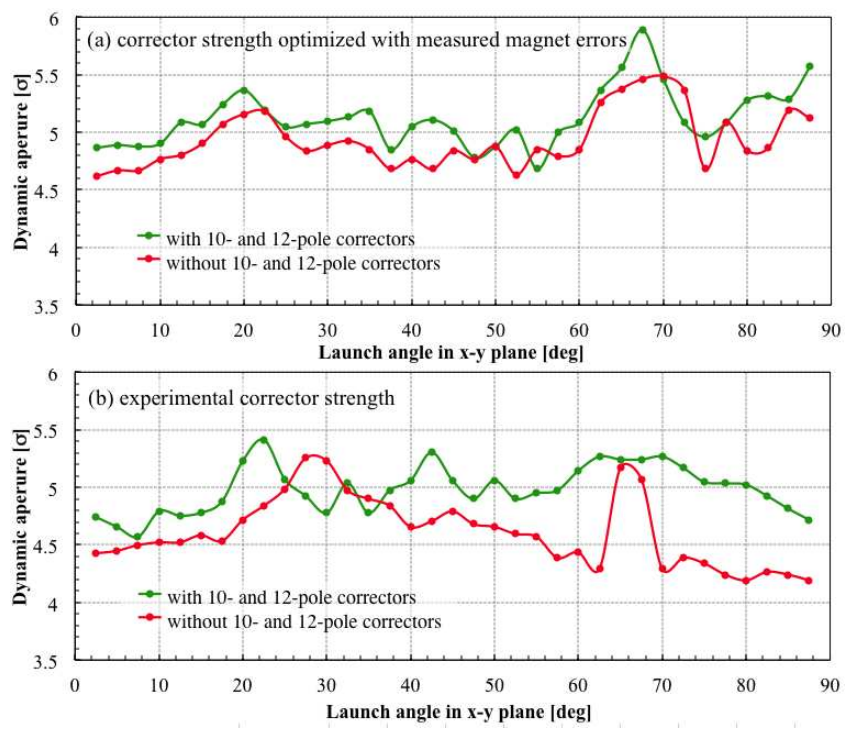

FIG. 6: Simulated dynamic aperture, in units of the rms beam size $\sigma$, as a function of the launch angle in the $x-y$ plane. In part (a) sextupole, skew sextupole, 10- and 12-pole corrector settings were calculated from measured magnet data. In part (b) sextupole, skew sextupole, 10- and 12-pole corrector values from the experiment are used.

In the measurements the effect of the 12-pole correctors on the beam loss rate was generally stronger than the effect of the 10-pole correctors. A comparison with calculated values of different methods shows agreement only in the magnitude of the corrector values.

For high-order multipole correctors to be effective the particle motion must be influenced by large enough nonlinearities. In RHIC such conditions just barely exist for polarized protons at $100 \mathrm{GeV}$ (below the maximum energy of $255 \mathrm{GeV}$ ) with $\beta^{*}=0.7 \mathrm{~m}$. A few scans during the $100 \mathrm{GeV}$ polarized proton run in 2012 with $\beta^{*}=0.85 \mathrm{~m}$ showed no beneficial effect of the $10-$ and 12-poles correctors [78]. We do not expect that 10- and 12 -pole correctors will lead to large performance gains in RHIC in the future. Instead, operating conditions such as $\beta^{*}$ will be chosen so that these correctors are ineffective. We expect that a similar strategy will be applied at other machines.

\section{ACKNOWLEDGMENTS}

The authors are thankful for discussions and comments to B. Holzer, A. Jain, M. Minty, C. Montag, F. Pilat, L. Rajulapati, V. Ptitsyn, and C. Zimmer, and acknowledge the full support of the Operations Group.

This work was supported by Brookhaven Science Associates, LLC under Contract No. DE-AC02-98CH10886 with the U.S. Department of Energy. 
[1] R.P. Walker, proceedings of the Particle Accelerator Conference 1981, Washington, DC, pp. 3056-3058 (1981).

[2] R. Brinkmann and F. Willeke, proceedings of the European Particle Accelerator Conference 1988, Rome, Italy, pp. 911-913 (1988).

[3] H. Brück et al., Z.Phys. C44, pp. 385-392 (1989).

[4] F. Willeke and F. Zimmermann, proceedings of the Particle Accelerator Conference 1991, San Francisco, CA, pp. 2483-2487 (1991).

[5] F. Zimmerman, Ph.D. thesis, University of Hamburg, DESY 93-059 (1993).

[6] D.A. Herrup, W. Kinney, M.J. Lamm, and A. Mokhtarani, Phys. Rev. E, Vol. 49, No 6, pp. 5660-5668 (1994).

[7] W. Fischer, Ph.D. thesis, University of Hamburg, DESY 95-235 (1993).

[8] B. Holzer and C. Montag, private communication.

[9] J. Peoples, proceedings of the European Particle Accelerator Conference 1988, Rome, Italy, pp. 237-241 (1988).

[10] J.M. Peterson and E. Forest, proceedings of the 1988 European Particle Accelerator Conference, Rome, Italy, pp. 827-829 (1988).

[11] D. Neuffer, proceedings of the 1989 Particle Accelerator Conference, Chicago, IL, USA, pp. 1432-1434 (1989).

[12] H. Edwards, proceedings of the European Particle Accelerator Conference 1990, Nice, France, pp. 356-360 (1990).

[13] S.R. Stampke, Y. Cai, and J. Skaritka, proceedings of the Particle Accelerator Conference 1991, San Francisco, CA, pp. 2218-2220 (1991).

[14] B.T. Leemann, proceedings of the Particle Accelerator Conference 1987, Washington, DC, pp. 1031-1033 (1987).

[15] G. Dugan, proceedings of the Particle Accelerator Conference 1993, Washington, DC, pp. 3717-3720 (1993).

[16] J. Skaritka, E. Kelly, W. Schneider, R. Shutt, P. Thompson, P. Wanderer, E. Willen, D. Bintinger, R. Coluccio, and L. Schieber, proceedings of the Particle Accelerator Conference 1987, Washington, DC, pp. 1437-1439 (1987).

[17] H. Hahn et al., Nucl. Instrum \& Methods, A 499, pp. 245-263 (2003).

[18] J. Claus, G.F. Dell, H. Hahn, G. Parzen, M.J. RhoadesBrown, and A.G. Ruggiero, proceedings of the European Particle Accelerator Conference 1990, Nice, France, pp. 1467-1469 (1990).

[19] M. Anerella et al., Nucl. Instrum \& Methods, A 499, pp. 280-315 (2003).

[20] J. Wei, BNL RHIC/AP/82 (1996).

[21] J. Wei, BNL RHIC/AP/105 (1996).

[22] J. Wei, BNL RHIC/AP/117 (1996).

[23] J.-P. Koutchouk, F. Pilat, and V. Ptitsyn, proceedings of the 2001 Particle Accelerator Conference, Chicago, IL, USA, pp. 1684-1686 (2001).

[24] F. Pilat, P. Cameron, V. Ptitsyn, and J.-P. Koutchouk, proceedings of the 2002 European Particle Accelerator Conference, Paris, France, pp. 12891-1283 (2002).

[25] N. Siegel, proceedings of the European Particle Accelerator Conference 2000, Vienna, Austria, pp. 23-27 (2000).

[26] O. Brüning, P. Collier, P. Lebrun, S. Myers, R. Ostojic, J. Poole, and P. Proudlock (editors), CERN-2004-003 (2004).

[27] A. Faus-Golfe and A. Verdier, proceedings of the 1996 European Particle Accelerator Conference, Sitges, Spain
(1996).

[28] A. Verdier and A. Faus-Golfe, proceedings of the 1997 Particle Accelerator Conference, Vancouver, BC, Canada, pp. - ; CERN LHC Project Report 116 (1997).

[29] H. Grote, F. Schmidt, and L.H.A. Leunissen, CERN LHC Project Note 197 (1999).

[30] A. Ijspeert and M. Karpinnen, in proceedings of the Workshop on LHC Interaction Region Correction Systems, BNL, BNL-52575, LHC-PROJECT-NOTE-199, pp. 78-86 (1999).

[31] W. Scandale and F. Schmidt, proceedings of the European Particle Accelerator Conference 1990, Nice, France, pp. 1470-1472 (1990).

[32] R. Bailey, F. Bordry, L. Bottura, P. Burla, P. Collier, K. Henrichson, J.-P. Koutchouk, R. Lauckner, R. Parker, J. Pett, P. Proudlock, H. Schmickler, R. Schmidt, L. Walkiers, and R. Wolf, proceedings of the Particle Accelerator Conference 1997, Vancouver, BC Canada, pp. 66-68 (1997).

[33] J.-P. Koutchouk, proceedings of the Particle Accelerator Conference 1999, New York, NY, pp. 372-376 (1999).

[34] Y. Papaphilipou, proceedings of the European Particle Accelerator Conference 2000, Vienna, Austria, pp. 10631065 (2000).

[35] O. Brüning, S. Fartoukh, A. Lombardi, T. Risselada, F. Schmidt, and A. Verdier, proceedings of the European Particle Accelerator Conference 2004, Lucerne, Switzerland, pp. 1885-1887 (2004).

[36] E.H. McLean, F. Schmidt, R. Tomas, R. Bartolini, E. Todesco, R. Steinhagen, G. Vanbavinckhove, and M. Giovannozzi, proceedings of the International Particle Accelerator Conference 2011, San Sebastian, Spain, pp. 21992201 (2011).

[37] O. Brüning, S. Farthoukh, M. Giovannozzi, and T. Risselada, CERN LHC Project Note 349 (2004).

[38] W. Fischer, V. Ptitsin, J. Wei, R. Ostojic, and J. Strait, in proceedings of the Workshop on LHC Interaction Region Correction Systems, BNL, BNL-52575, LHCPROJECT-NOTE-199, pp. 50-53 (1999).

[39] T. Sen, N. Gelfand, and W. Wan, in proceedings of the Workshop on LHC Interaction Region Correction Systems, BNL, BNL-52575, LHC-PROJECT-NOTE-199, pp. 64-70 (1999).

[40] J. Shi, in proceedings of the Workshop on LHC Interaction Region Correction Systems, BNL, BNL-52575, LHCPROJECT-NOTE-199, pp. 71-77 (1999).

[41] J. Wei, in proceedings of the Workshop on LHC Interaction Region Correction Systems, BNL, BNL-52575, LHCPROJECT-NOTE-199, pp. 87-91 (1999).

[42] W. Fischer, V. Ptitsin, J. Wei, R. Ostojic, and J. Strait, in proceedings of the Workshop on LHC Interaction Region Correction Systems, BNL, BNL-52575, LHCPROJECT-NOTE-199, pp. 92-94 (1999).

[43] V. Ptitsin, W. Fischer, and J. Wei, in proceedings of the Workshop on LHC Interaction Region Correction Systems, BNL, BNL-52575, LHC-PROJECT-NOTE-199, pp. 95-97 (1999).

[44] J. Wei, V. Ptitsin, F. Pilat, S. Tepikian, N. Gelfand, W. Wan, and J. Holt, proceedings of the 1999 Particle Accelerator Conference, New York, NY, USA, pp. 380383 (1999). 
[45] V. Ptitsin, S. Tepikian, and J. Wei, proceedings of the 1999 Particle Accelerator Conference, New York, NY, USA, pp. 1575-1577 (1999).

[46] J. Wei, W. Fischer, V. Ptitsin, R. Ostojic, and J. Strait, proceedings of the 1999 Particle Accelerator Conference, New York, NY, USA, pp. 2921-2923 (1999).

[47] R. Tomaás, M. Aiba, C. Alabau, O. Brüning, R. Calaga, M. Giovannozzi, V. Kain, P. Hagen, M. Lamont, R. Miyamoto, F. Schmidt, M. Strzelczyk, and G. Vanbavinckhove, in proceedings of the 2nd Evian workshop on LHC Beam Operation, Evian-les-Bains, CERN-ATS2011-017, pp. 211-223 (2011).

[48] R. Tomás, M. Giovannozzi, and R. de Maria, Phys. Rev. ST - Accel. Beams 12, 011002 (2009).

[49] O. Bruüning, proceedings of the European Particle Accelerator Conference 2006, Edinburgh, UK, pp. 14-18 (2006).

[50] J. Wenniger, R. Alemany-Fernandez, G. Arduini, R. Assmann, B. Holzer, E.B. Holzer, V. Kain, M. Lamont, A. Macpherson, G. Papotti, M. Pojer, L. Ponce, S. Redaelli, M. Solfaroli Camillocci, J. Uythoven, W. Venturi Delsolaro, proceedings of the International Particle Accelerator Conference 2012, New Orleans, Louisiana, USA, pp. 3767-3769 (2006).

[51] R. Tomás, Phys. Rev. ST - Accel. Beams 9, 081001 (2006).

[52] B. Parker, M. Anerella, J. Escallier, P. He, A. Jain, A. Marone, P. Wanderer, K.C. Wu, C. Hauviller, E. Marin, R. Tomás, F. Zimmermann, B. Bolzen, A. Jeremie, N. Kimura, K. Kubo, T. Kume, D. Kuroda, T. Okugi, T. Tauchi, N. Terunuma, T. Tomaru, K. Tsuchiya, J. Urakawa, A. Yamamoto, P. Bambade, P. Coe, D. Urner, A. Seryi, C. Spencer, and G. White, proceedings of the International Particle Accelerator Conference 2010, Kyoto, Japan, pp. 3440-3442 (2010).

[53] M. Rehak, G. Danby, J. Bengtsson, J. Jackson, J. Skaritka, C. Spataro, proceedings of the Particle Accelerator Conference 2009, Vancouver, BC Canada, pp. 139-141 (2009).

[54] S.C. Leemann and A. Streun, Phys. Rev. ST - Accel. Beams 14, 030701 (2011).

[55] H. Huang, L. Ahrens, E.C. Aschenauer, G. Atoian, M. Bai, A. Bazilevsky, M. Blaskiewicz, J.M. Brennan, K.A. Brown, D. Bruno, A. Dion, K.A. Drees, W. Fischer, J.W. Glenn, X. Gu, L.T. Hoff, C. Liu, Y. Luo, W.W. MacKay, Y. Makdisi, G.J. Marr, A. Marusic, F. Meot, M. Minty, C. Montag, J. Morris, A. Poblaguev, V. Ptitsyn, G. Robert-Demolaize, T. Roser, W.B. Schmidke, V. Schoefer, D. Smirnov, S. Tepikian, J. Tuozzolo, G. Wang, K. Yip, A. Zaltsman, A. Zelenski, S.Y. Zhang, I.G. Alekseev, and D. Svirida, proceedings of the 2011 International Particle Accelerator Conference, Barcelona, Spain, pp. 1888-1890 (2011).

[56] G.J. Marr, L. Ahrens, M. Bai, J. Beebe-Wang, I. Blackler, M. Blaskiewicz, J.M. Brennan, K.A. Brown, D. Bruno, J. Butler, C. Carlson, R. Connolly, T. D'Ottavio, K.A. Drees, A.V. Fedotov, W. Fischer, W. Fu, C.J. Gardner, D.M. Gassner, J.W. Glenn, X. Gu, M. Harvey, T. Hayes, L.T. Hoff, H. Huang, P. Ingrassia, J. Jamilkowski, N.A. Kling, M. Lafky, J.S. Laster, C. Liu, Y. Luo, M. Mapes, A. Marusic, K. Mernick, R. Michnoff, M. Minty, C. Montag, J. Morris, C. Naylor, S. Nemesure, S. Polizzo, V. Ptitsyn, G. Robert-Demolaize, T. Roser, P.W. Sampson, J. Sandberg, V. Schoefer, C. Schultheiss, F. Sev- erino, T. Shrey, K. Smith, D. Steski, S. Tepikian, P. Thieberger, D. Trbojevic, N. Tsoupas, J. Tuozzolo, B. Van Kuik, G. Wang, M. Wilinski, A. Zaltsman, K. Zeno, and S.Y. Zhang, proceedings of the 2011 International Particle Accelerator Conference, Barcelona, Spain, pp. 1894-1896 (2011).

[57] www.rhichome.bnl.gov/RHIC/Runs

[58] A.V. Fedotov, W. Fischer, S. Tepikian, and J. Wei, proceedings of the 39th ICFA Advanced Beam Dynamics Workshop on High Intensity High Brightness Hadron Beams HB2006, Tsukuba, Japan (2006).

[59] J.M. Brennan, M. Blaskiewicz, and F. Severino, Phys. Rev. Lett. 100, 174802 (2008).

[60] J.M. Brennan, M. Blaskiewicz, and K. Mernick, Phys. Rev. Lett. 105, 09801 (2010).

[61] C. Montag, R. Bonati, J.M. Brennan, J. Butler, P. Cameron, G. Ganetis, P. He, W. Hirzel, L.X. Jia, P. Koello, W. Louie, G. McIntyre, A. Nicoletti, J. Rank, T. Roser, T. Satogata, J. Schmalzle, A. Sidi-Yekhlef, J. Sondericker, and T. Tallerico, Nucl. Instrum. \& Methods A 564, pp. 26-31 (2006).

[62] R. Michnoff, L. Arnold, L. Carboni, P. Cerniglia, A. Curcio, L. DeSanto, C. Folz, C. Ho, L. Hoff, R. Hulsart, R. Karl, C. Liu, Y. Luo, W.W. MacKay, G. Mahler, W. Meng, K. Mernick, M. Minty, C. Montag, R.H. Olsen, J. Piacentino, P. Popken, R. Przybylinski, V. Ptitsyn, J. Ritter, R. Schoenfeld, P. Thieberger, J. Tuozzolo, A. Weston, J. White, P. Ziminski, and P. Zimmermann, proceedings of the 2011 Particle Accelerator Conference, New York, NY, USA, pp. 609-611 (2011).

[63] C. Montag, L. Ahrens, M. Bai, J. Beebe-Wang, M. Blaskiewicz, J.M. Brennan, K.A. Brown, D. Bruno, R. Connolly, T. D'Ottavio, A. Drees, A.V. Fedotov, W. Fischer, G. Ganetis, C.J. Gardner, J.W. Glenn, H. Hahn, M. Harvey, T. Hayes, H. Huang, P. Ingrassia, J. Jamilkowski, D. Kayran, J. Kewisch, R.C. Lee, D. Lowenstein, A.U. Luccio, Y. Luo, W.W. MacKay, Y. Makdisi, N. Malitsky, G.J. Marr, A. Marusic, M.P. Menga, R. Michnoff, M. Minty, J. Morris, B. Oerter, F.C. Pilat, P. Pile, E. Pozdeyev, V. Ptitsyn, G. Robert-Demolaize, T. Roser, T. Russo, T. Satogata, V. Schoefer, C. Schultheiss, F. Severino, M. Sivertz, K. Smith, S. Tepikian, P. Thieberger, D. Trbojevic, N. Tsoupas, J. Tuozzolo, A. Zaltsman, A. Zelenski, K. Zeno, and S.Y. Zhang, proceedings of the 2010 International Particle Accelerator Conference, Kyoto, Japan, pp. 531-533 (2010).

[64] D. Raparia, J. Alessi, B. Briscoe, J. Fite, O. Gould, A. Kponou, V. Lo Destro, M. Okamura, J. Ritter, and A. Zelenski, proceedings of the 2009 Particle Accelerator Conference, Vancouver, BC, Canada, pp. 411-413 (2009).

[65] K.A. Brown, L. Ahrens, C. Gardner, D. Gassner, D. Raparia, D. Steski, P. Thieberger, and K. Zeno, proceedings of the 2009 Particle Accelerator Conference, Vancouver, BC, Canada, pp. 3729-3732 (2009).

[66] M.A. Furman and M.S. Zisman, "Luminosity", in "Handbook of accelerator physics and engineering", (A.W. Chao and M. Tigner eds.), World Scientific (1999).

[67] F. Pilat, S. Binello, P. Cameron, and V. Ptitsyn, proceedings of the 2003 Particle Accelerator Conference, Portland, OR, USA, pp. 1703-1705 (2003).

[68] F. Pilat, Y. Luo, N. Malitsky, and V. Ptitsyn, proceedings of the 2005 Particle Accelerator Conference, Knoxville, TN, USA, pp. 3729-3732 (2009).

[69] C. Zimmer, S. Binello, M. Minty, and F. Pilat, proceed- 
ings of the 2010 International Particle Accelerator Conference, Kyoto, Japan, pp. 2255-2254 (2010).

[70] Y. Luo, M. Bai, J. Beebe-Wang, J. Bengtsson, R. Calaga, W. Fischer, A.K. Jain, N. Malitsky, S. Peggs, F. Pilat, V. Ptitsyn, G. Robert-Demolaize, T. Satogata, S. Tepikian, D. Trbojevic, and R. Tomás, proceedings of the 2009 Particle Accelerator Conference, Vancouver, BC, Canada, pp. 2489-2491 (2009).

[71] Y. Luo, F. Pilat, V. Ptitsyn, D. Trbojevic, and J. Wei, BNL C-AD/AP/160 (2004); proceedings of the 2005 Particle Accelerator Conference, Knoxville, TN, USA, pp. 2116-2118 (2005).

[72] K.-H. Mess, P. Schmüser, and S. Wolff, "Superconducting Accelerator Magnets", World Scientific (1996).

[73] V. Ziemann, proceedings of the European Particle Accelerator Conference 2002, Paris, France, pp. 1217-1219 (2002).
[74] P. Cameron, P. Cirniglia, R. Connolly, J. Cupolo, C. Degan, K.A. Drees, D. Gassner, M. Kesselman, R. Lee, T. Satogata, B. Sikora, and R. Witkover, proceedings of DIPAC 2001, Grenoble, France, pp. 41-45 (2001).

[75] Bergoz Beam Instrumentation, www.bergoz.com

[76] Y. Luo, proceedings of the 2010 International Particle Accelerator Conference, Kyoto, Japan, pp. 1907-1908 (2010).

[77] J. Beebe-Wang and A. Jain, proceedings of the 2007 Particle Accelerator Conference, Albuquerque, NM, USA, pp. 4309-4311 (2007).

[78] C. Zimmer, private communication (2012).

[79] This is the now commonly used European notation. Previously the American notation had $b_{0}$ for a dipole coefficient etc. A large number of references in the paper still use the American notation. 